\title{
Graves' orbitopathy as a rare disease in Europe: a European Group on Graves' Orbitopathy (EUGOGO) position statement
}

\author{
P. Perros ${ }^{1,20^{*}}$ (D), L. Hegedüs ${ }^{2}$, L. Bartalena ${ }^{3}$, C. Marcocci ${ }^{4}$, G. J. Kahaly ${ }^{5}$, L. Baldeschi ${ }^{6}$, M. Salvi ${ }^{7}$, J. H. Lazarus ${ }^{8}$, \\ A. Eckstein ${ }^{9}$, S. Pitz ${ }^{10}$, K. Boboridis ${ }^{11}$, P. Anagnostis ${ }^{12}$, G. Ayvaz ${ }^{13}$, A. Boschi ${ }^{6}$, T. H. Brix ${ }^{2}$, N. Curró ${ }^{14}$, O. Konuk ${ }^{15}$, \\ M. Marinò ${ }^{4}$, A. L. Mitchell ${ }^{1}$, B. Stankovic ${ }^{16}$, F. B. Törüner ${ }^{13}$, G. von Arx ${ }^{17}$, M. Zarković $^{18}$ and W. M. Wiersinga ${ }^{19}$
}

\begin{abstract}
Background: Graves' orbitopathy (GO) is an autoimmune condition, which is associated with poor clinical outcomes including impaired quality of life and socio-economic status. Current evidence suggests that the incidence of GO in Europe may be declining, however data on the prevalence of this disease are sparse. Several clinical variants of $\mathrm{GO}$ exist, including euthyroid GO, recently listed as a rare disease in Europe (ORPHA466682). The objective was to estimate the prevalence of $\mathrm{GO}$ and its clinical variants in Europe, based on available literature, and to consider whether they may potentially qualify as rare. Recent published data on the incidence of GO and Graves' hyperthyroidism in Europe were used to estimate the prevalence of GO. The position statement was developed by a series of reviews of drafts and electronic discussions by members of the European Group on Graves' Orbitopathy. The prevalence of GO in Europe is about 10/10,000 persons. The prevalence of other clinical variants is also low: hypothyroid GO 0.02-1.10/10,000; GO associated with dermopathy 0.15/10,000; GO associated with acropachy 0.03/10,000; asymmetrical GO 1.00-5.00/10,000; unilateral GO 0.50-1.50/10,000.
\end{abstract}

Conclusion: $\mathrm{GO}$ has a prevalence that is clearly above the threshold for rarity in Europe. However, each of its clinical variants have a low prevalence and could potentially qualify for being considered as a rare condition, providing that future research establishes that they have a distinct pathophysiology. EUGOGO considers this area of academic activity a priority.

Keywords: Graves' orbitopathy, Ophthalmopathy, Prevalence, Incidence, Epidemiology, Rare disease, EUGOGO

\section{Background}

Graves' orbitopathy (GO) (ICD-10 H06.2) [1] is an autoimmune condition that targets the orbits [2] and is responsible for significant morbidity $[3,4]$ including, in rare cases, blindness [5]. The pathogenesis of GO is closely linked to thyroid autoimmunity [2]. Autoimmune thyroid diseases share a common genetic background, but display widely varying and overlapping clinical phenotypes [6]. Among them, GO is the most striking extra-thyroidal manifestation and the hardest to treat $[5,7]$. GO has been described as a rare disease by several authors [8-12], however meaning "uncommon" without a precise definition and to date no direct population surveys of prevalence are available. Rare disease status can raise public awareness and encourage research, leading to improved patient care [13], much of which is needed for patients with GO [14].

The objective of this position statement was to estimate the prevalence of GO and its clinical variants in Europe, based on available literature, and to explore whether rare disease designation may be appropriate.

\section{Methods \\ A task force was identified by the officers of the European Group on Graves' Orbitopathy (EUGOGO). The lead author performed a literature search using PubMed with}

\footnotetext{
* Correspondence: petros.perros@ncl.ac.uk

'Institute of Genetic Medicine, Newcastle University, Central Parkway, Newcastle upon Tyne, Tyne NE1 3BZ, UK

${ }^{20}$ Department of Endocrinology, Level 6, Leazes Wing, Royal Victoria

Infirmary, Newcastle upon Tyne NE1 4LP, UK

Full list of author information is available at the end of the article
}

(c) The Author(s). 2017 Open Access This article is distributed under the terms of the Creative Commons Attribution 4.0 International License (http://creativecommons.org/licenses/by/4.0/), which permits unrestricted use, distribution, and reproduction in any medium, provided you give appropriate credit to the original author(s) and the source, provide a link to the Creative Commons license, and indicate if changes were made. The Creative Commons Public Domain Dedication waiver (http://creativecommons.org/publicdomain/zero/1.0/) applies to the data made available in this article, unless otherwise stated. 
the key terms "Graves' orbitopathy", "Graves' ophthalmopathy", "thyroid eye disease" and "prevalence", "epidemiology", "incidence", "rare disease", "orphan". Based on the results of the literature search, a brief review of the available evidence and a list of questions relevant to the topic of $\mathrm{GO}$ as a rare disease was drafted and circulated to members of the task force for approval. All members of EUGOGO were invited to contribute if they so wished. Topics were allocated to individual authors who were asked to perform additional literature searches and summarise, appraise and comment on the evidence. The submissions from individual members were circulated for review and comment, leading to further discussions, amendments and the final draft.

The prevalence of GO was estimated from publications on the incidence of GO and Graves' hyperthyroidism (ICD-10, E05.0) [1]. The literature search was limited to studies of patient cohorts derived from European populations that completed recruitment after 2005, in order to capture most recent trends given that the focus of our interest is Europe, and that the epidemiology of GO seems to be changing over time [11, 15-17]. The literature search on the incidence of Graves' hyperthyroidism yielded 366 publications. Of these, only three studies met the above criteria [18-20]; Table 1.

The prevalence of Graves' hyperthyroidism, from incidence data, was estimated using established methodologies for calculating global burden of disease [21-23] and the software DisMod II [24]. This is based on a simple model that formalises the relation between incidence (age and sex adjusted), general mortality, case-fatality and prevalence. We assumed that the duration of GO is lifelong (though some cases of GO are transient, but difficult to quantify) and that the relative risk of dying due to Graves' hyperthyroidism is 1.28 (95\% CI 1.21-1.36), based on data from Brandt et al. [25]. It was further assumed that within the general population an individual will either acquire GO, or die from a GO-unrelated cause; that patients with GO will either die from a GO-related, or from a GO-unrelated cause; and that the influence of the incidence of a rare disease on the general population is negligible. It follows that the number of subjects within a stable general population at any given moment will depend on the mortality rate and GO incidence, while the number of GO patients will depend on GO incidence, case fatality and general mortality rate. If GO incidence, case fatality and general mortality rate are constant, a set of ordinary differential equations can be defined to characterise movement between general population, diseased, and dead [24].

\section{Results and discussion}

The available data on incidence of GO and Graves' disease in Europe are limited, but are derived from different geographical areas, are large and internally consistent, and therefore reliable for the purposes of estimating prevalence of GO.

\section{Calculation of prevalence of $\mathrm{GO}$ from incidence of $\mathrm{GO}$}

The data provided by one of the major publications on the incidence of GO [20] did not include age-specific intervals. However, the authors stated that "age distribution differed in GO and Graves' hyperthyroidism, with GO being less than $2 \%$ of Graves' hyperthyroidism at age $20-40$ year and $8 \%$ at age $40-60$ year." We therefore estimated age and sex-specific incidences derived from [20] and used them to calculate prevalence (Table 2).

This is the only study which directly assessed the incidence of GO in a large European population prospectively and included new cases between 1992 and 2011, based on approximately 8.9 million person-years of observation [20]. The incidence of moderate-to-severe GO was 0.161 / $10,000 /$ year with a median age at onset of 50 years [20]. Mild cases of GO were not included due to difficulties in defining mild GO in large-scale epidemiological surveys. Distinguishing mild GO from normality and from the transient ocular effects of thyrotoxicosis of any cause, can be a challenge, especially if multiple observers are involved with variable degrees of expertise. In recent cross-sectional studies from secondary or tertiary centres, conducted by highly trained observers and with well-defined criteria for GO, about $65 \%$ of all cases of GO were found to have mild GO, and about $2 \%$ sightthreatening, disease $[11,16]$. We assumed that the cases of mild GO which were excluded by Laurberg et al. [20], accounted for 2/3 (65\%) of all cases of GO. Hence, the adjusted figure for incidence of all grades of severity of GO, based on the above studies $[11,16,20]$, is $0.483 / 10,000 /$ year (incidence of moderate-to-severe disease 0.161 multiplied by 3 , in view of the fact that it represents $1 / 3$ of all cases $=0.483$ ). The data published by Laurberg et al. [20] are unclear as to whether sight-

Table 1 Characteristics of studies selected for estimation of prevalence of GO

\begin{tabular}{|c|c|c|c|c|}
\hline Study & Study population & Country & Years studied & Type of study \\
\hline Abraham-Nordling et al. [18] & $\begin{array}{l}3.5 \text { million general } \\
\text { population }\end{array}$ & Sweden & $2003-2005$ & $\begin{array}{l}\text { Prospective, population registry-based, reporting on incidence } \\
\text { of Graves' hyperthyroidism and all grades of severity of GO }\end{array}$ \\
\hline Zaletel et al. [19] & $\begin{array}{l}1.0 \text { million general } \\
\text { population }\end{array}$ & Slovenia & 1999-2009 & $\begin{array}{l}\text { Single institution, prospective cohort study of patients with } \\
\text { thyroid disease, including Graves' hyperthyroidism as a subgroup }\end{array}$ \\
\hline Laurberg et al. [20] & $\begin{array}{l}0.5 \text { million general } \\
\text { population }\end{array}$ & Denmark & 1992-2011 & $\begin{array}{l}\text { Single institution, prospective cohort study, reporting on } \\
\text { incidence of moderate-to- severe GO }\end{array}$ \\
\hline
\end{tabular}


Table 2 Estimated age and sex-specific incidences derived from Laurberg et al. [20]. These figures were used to calculate prevalence of GO

\begin{tabular}{lll}
\hline Age (years) & \multicolumn{2}{l}{ Incidence of GO (cases/10,000/year) } \\
\cline { 2 - 3 } & Female & Male \\
\hline $0-20$ & 2.7 & 0.005 \\
$20-40$ & 6.7 & 0.014 \\
$40-60$ & 26.7 & 0.054 \\
$>60$ & 13.4 & 0.027 \\
\hline
\end{tabular}

threatening GO was included within the moderate-tosevere category. We therefore used the frequency of sight-threatening GO of $2 \%$ cited by other publications $[11,16]$ to calculate the prevalence of sight-threatening GO from data by [20]. Using the approach described in "methods" the prevalence of GO is estimated to be $8.97 / 10,000$ population. It can be further broken down to mild $(5.83 / 10,000)$, moderate-to-severe $(2.96 / 10,000)$ and sight-threatening GO $(0.18 / 10,000)$ (Table 3a).

\section{Calculation of prevalence of GO from incidence of Graves' hyperthyroidism}

Based on data for incidence of Graves' hyperthyroidism, the calculated incidence of GO in Europe has been reported to be 10-30/10,000/year [26-28]. These studies relate to epidemiological data collected $10-20$ years ago and the estimates may not be valid today since the incidence of GO appears to be declining $[11,14,15]$ although this may be partly due changing referral patterns. In a recent study, Abraham-Nordling et al. [18] reported the incidence of Graves' hyperthyroidism derived from a Swedish population of about 3.5 million. The incidence of Graves' hyperthyroidism was 2.10/10,000/year. Mild ("non-infiltrative") GO was present in $15.2 \%$ of patients with Graves' hyperthyroidism and moderate-to-severe/sight-threatening (infiltrative) in $4.9 \%$ of cases. Thus, the incidence of all cases of GO was 0.42/10,000/year (incidence of mild GO 0.32/10,000/year and of moderate-to-severe/sight-threatening 0.10/10,000/ year) [18]. Using the same methodology for calculating prevalence as before, the prevalence of GO is shown in Table 3a. The study by Zaletel et al. [19] yielded remarkably similar results for the incidence of Graves' hyperthyroidism as that by Abraham-Nordling et al. [18] (2.08/10,000/year), and identical figures for the prevalence of GO (Table 3a).

The figures for overall prevalence of GO derived from [18] and [20] vary almost by a factor of 2 . The reason is unclear but it may represent a true variation in different populations, or may be accounted for by the different methodologies in identifying cases. Laurberg et al. [20] presumed that all patients with moderate-to-severe GO were seen in a single tertiary centre. Hence, the data have included some patients with GO seen elsewhere and patients who were not referred. The other study [18] identified patients with Graves' hyperthyroidism through a registry and it may have captured more cases. One of the weaknesses of our calculations is that the estimates of prevalence of GO are derived from a small $(n=3)$ number of epidemiological studies. However, this is all that is available in the recent literature and it is unlikely that more extensive data will be forthcoming for a while. The consistency between the figures from the three studies quoted above is sufficient in our view to justify estimates of prevalence based on these data.

\section{Prevalence of variants of GO}

A number of distinct clinical variants of GO exist, however these are poorly studied and deserve attention. Euthyroid/

Table 3 Estimated prevalence of GO and variants of GO. (a) shows prevalence by severity and (b) for clinical variants (all grades of severity)

PREVALENCE (per 10,000 population) PROPORTION OF PATIENTS WITH VARIANT $\quad$ SOURCE

\begin{tabular}{|c|c|c|c|}
\hline \multicolumn{4}{|l|}{ (a) } \\
\hline All cases of $\mathrm{GO}$ & 8.97 & - & [18] \\
\hline & 15.48 & & {$[19,20]$} \\
\hline \multirow[t]{2}{*}{ Mild GO } & 5.83 & $65.0 \%$ & [18] \\
\hline & 11.03 & $72.8 \%$ & {$[19,20]$} \\
\hline Moderate-to-severe & $2.96-4.45$ & $33.0-29.4 \%$ & [18-20] \\
\hline Sight-threatening & 0.18 & $2.0 \%$ & {$[11,14]$} \\
\hline \multicolumn{4}{|l|}{ (b) } \\
\hline Euthyroid/hypothyroid GO & $0.02-1.10$ & $0.2-11.0 \%$ & [29-33] \\
\hline GO associated with dermopathy & 0.15 & $1.5 \%$ & {$[7]$} \\
\hline GO associated with acropachy & 0.03 & $0.3 \%$ & [7] \\
\hline Asymmetrical GO & $1.00-5.00$ & $10.0-50.0 \%$ & [34-36] \\
\hline Unilateral GO & $0.50-1.50$ & $5.0-15.0 \%$ & [35-38] \\
\hline
\end{tabular}


hypothyroid $\mathrm{GO}$ is a variant comprising of patients who are euthyroid, or have overt or subclinical hypothyroidism, before or within 6-12 months after the onset of GO and constitutes $0.2-11 \%$ of all cases of GO [29-33]. Patients with GO associated with dermopathy have characteristic skin changes and comprise 1.5\% of all cases of GO [7]. Patients with $\mathrm{GO}$ associated with acropachy display typical nail and subperiosteal changes and make up $0.3 \%$ of all cases of GO [7]. Asymmetrical GO, usually defined as a difference of $\geq 2 \mathrm{~mm}$ in proptosis between the two eyes, is reported to occur in $10-50 \%$ of patients with GO [30, 34-36]. Unilateral GO, defined as one of more features of GO in one eye without any in the contralateral eye, is reported to occur with a frequency of $5-15 \%$ of all cases of GO [35-38]. Previously reported data on the frequency of euthyroid and asymmetrical/unilateral GO are likely to be overestimates as awareness of IgG4-related ophthalmic disease has been low $[39,40]$, but is impossible to quantify. The estimated prevalence of these variants (inclusive of all grades of severity) based on the previously estimated overall prevalence of GO of approximately 10/10,000 population, and the reported frequencies of the variants is shown in Table $3 \mathrm{~b}$.

One of our assumptions in calculating the prevalence of $\mathrm{GO}$ was that the duration of $\mathrm{GO}$ is life-long. In a minority of patients this is not the case. In a study published 20 years ago by Bartley et al. [41], 40\% of patients responding by questionnaire reported that their eyes were normal 10 years after the diagnosis of $\mathrm{GO}$, but this was not possible to confirm objectively. A study published in 2002 by Terwee and colleagues [42] reported on outcomes in a cohort of patients after 11.7 years of follow-up, but the data did not report on the frequency of complete regression of the features of GO. In a more recent study a significant proportion of patients had transient GO [11]. However, this was a selected group of patients with Graves' hyperthyroidism who had no GO at the time of recruitment and were treated with anti-thyroid drugs, from a single institution. It is therefore impossible to correct for transient GO with an acceptable degree of confidence without taking a risk to over-state the case for variants of GO being rare. However, it is important to highlight that the data in Table 3 are likely to be overestimates of the prevalence of GO.

Designation of rare disease in Europe requires that several conditions be satisfied: prevalence of less than 5 per 10,000 population [43], distinct phenotype, distinct aetiology and mechanism of pathogenesis [44] and seriously debilitating or life-threatening impact on patients [45]. Euthyroid GO achieved rare disease status on the basis of the above criteria, and the consideration that the euthyroid status of such patients reflects mechanistically unique processes that are distinct from Graves' hyperthyroidism. We speculate that the other clinical variants described above may also have underlying unique and distinct pathogenetic processes from Graves' hyperthyroidism and each other. Future research focusing on deep phenotyping and molecular characteristics of variants of GO is likely to be productive in understanding the pathogenesis of GO.

\section{Conclusions}

GO has a prevalence that is clearly above the threshold for rarity in Europe. However, each of its clinical variants have a low prevalence and could potentially qualify for being considered as a rare condition, providing that future research establishes that they have a distinct pathophysiology. EUGOGO considers this area of academic activity a priority.

\section{Abbreviations}

EUGOGO: European Group on Graves' Orbitopathy; GO: Graves' orbitopathy

\section{Acknowledgements}

Not applicable.

\section{Funding}

None.

\section{Availability of data and material}

Data sharing not applicable to this article as no datasets were generated or analysed during the current study.

\section{Authors' contributions}

PP drafted the first version, performed the initial literature searches and coordinated the corrections, comments and criticisms of other co-authors. $M Z$ performed the statistical analyses. $L H, L B, C M, G J K, L B, M S, J H L, A E, S P, K B$, PA, GA, AB, THB, NC, OK, MM, ALM, BS, FBT, GVA, MZ and WMW performed additional literature searches were involved in drafting and revising the manuscript, revising it critically for important intellectual content and gave final approval of the version to be published. Each author has participated sufficiently in the work to take public responsibility for appropriate portions of the content and agreed to be accountable for all aspects of the work in ensuring that questions related to the accuracy or integrity of any part of the work are appropriately investigated and resolved.

\section{Competing interests}

PP and MS received consultancy fees from Roche Products Limited in 2016. WW, CM, MS and GK received consultancy fees in 2015 from River Vision Development Corporation. GK and MS are currently participating in a clinical trial of Teprotumumab in Graves' orbitopathy, sponsored by River Vision Development Corporation. All other authors declare that they have no competing interests.

\section{Consent for publication}

Not applicable.

Ethics approval and consent to participate Not applicable.

\section{Publisher's Note}

Springer Nature remains neutral with regard to jurisdictional claims in published maps and institutional affiliations.

\section{Author details}

${ }^{1}$ Institute of Genetic Medicine, Newcastle University, Central Parkway, Newcastle upon Tyne, Tyne NE1 3BZ, UK. ²Department of Endocrinology and Metabolism, Odense University Hospital, Odense 5000, Denmark. ${ }^{3}$ Endocrine Unit, University of Insubria, Ospedale di Circolo, Viale Borri, 5721100 Varese, Italy. ${ }^{4}$ Department of Clinical and Experimental Medicine, Section of Endocrinology, University of Pisa, Via Paradisa 2, 56124 Pisa, Italy. ${ }^{5}$ Department of Medicine I, Johannes Gutenberg University Medical Center, Mainz 55101, Germany. ${ }^{6}$ Department of Ophthalmology, Université Catholique de Louvain, Cliniques Universitaires Saint-Luc, Brussels, Belgium. 
'Graves' Orbitopathy Center, Endocrinology, Fondazione Ca' Granda IRCCS, Department of Medical and Community Sciences, University of Milan, Milan, Italy. Institute of Molecular and Experimental Medicine, Cardiff University School of Medicine, Cardiff, United Kingdom. ${ }^{9}$ Department of Ophthalmology, D-45122 University of Duisburg-Essen, Essen, Germany. ${ }^{10}$ Department of Ophthalmology, Johannes Gutenberg University Medical Center, Mainz 551331, Germany. ${ }^{11}$ 3rd University Department of Ophthalmology, Aristotle University of Thessaloniki, 1 Kyriakidi Street, 54636 Thessaloniki, Greece. ${ }^{12}$ Department of Endocrinology and Diabetes, Hippokration Hospital of Thessaloniki, Thessaloniki, Greece. ${ }^{13}$ Department of Endocrinology and Metabolism, Gazi University, Faculty of Medicine, Besevler, Ankara 06500, Turkey. ${ }^{14}$ Department of Ophthalmology, Fondazione IRCCS $\mathrm{Ca}^{\prime}$ Granda Ospedale Maggiore Policlinico, Milan, Italy. ${ }^{15}$ Department of Ophthalmology, Gazi University Faculty of Medicine, Besevler, Ankara 06500, Turkey. ${ }^{16}$ Faculty of Medicine University of Belgrade, Institute of Ophthalmology Clinical Centre of Serbia, Belgrade, Serbia. ${ }^{17}$ Basedow.ch Interdisciplinary Centre for Graves' Orbitopathy, Fährweg 10, 4600 Olten, Switzerland. ${ }^{18}$ School of Medicine, University of Belgrade, Clinic of Endocrinology, Clinical Centre of Serbia, Belgrade, Serbia. ${ }^{19}$ Academic Medical Center, 226601100 DD Amsterdam, Netherlands. ${ }^{20}$ Department of Endocrinology, Level 6, Leazes Wing, Royal Victoria Infirmary, Newcastle upon Tyne NE1 4LP, UK

Received: 11 January 2017 Accepted: 5 April 2017 Published online: 20 April 2017

\section{References}

1. http://apps.who.int/classifications/icd10/browse/2010/en. Accessed 7 Jan 2017.

2. Smith TJ, Hegedüs L. Graves' Disease. N Engl J Med. 2016;375:1552-65.

3. Ponto KA, Merkesdal S, Hommel G, Pitz S, Pfeiffer N, Kahaly GJ. Public health relevance of Graves' orbitopathy. J Clin Endocrinol Metab. 2013;98:145-52.

4. Brandt F, Thvilum M, Almind D, Christensen K, Green A, Hegedüs L, et al Morbidity before and after the diagnosis of hyperthyroidism: a nationwide register-based study. PLoS One. 2013;8:e66711

5. McKeag D, Lane C, Lazarus JH, Baldeschi L, Boboridis K, Dickinson AJ, et al. European Group on Graves' Orbitopathy (EUGOGO). Clinical features of dysthyroid optic neuropathy: a European Group on Graves' Orbitopathy (EUGOGO) survey. Br J Ophthalmol. 2007:91:455-8.

6. Wiersinga WM. Thyroid autoimmunity. Endocr Dev. 2014;26:139-57.

7. Bartalena L, Fatourechi V. Extrathyroidal manifestations of Graves' disease: a 2014 update. J Endocrinol Invest. 2014;37:691-700.

8. Perros P, Neoh C, Dickinson J. Thyroid eye disease. BMJ. 2009;338:b560.

9. Melcescu E, Horton WB, Kim D, Vijayakumar V, Corbett JJ, Crowder KW, et al. Graves orbitopathy: update on diagnosis and therapy. South Med J. 2014:107:34-43.

10. Bartalena L. Graves' Orbitopathy: Imperfect Treatments for a Rare Disease. Eur Thyr J. 2013:2:259-69.

11. Tanda ML, Piantanida E, Liparulo L, Veronesi G, Lai A, Sassi L, et al. Prevalence and natural history of Graves' orbitopathy in a large series of patients with newly diagnosed graves' hyperthyroidism seen at a single center. J Clin Endocrinol Metab. 2013;98:1443-9.

12. Wiersinga WM. Combined Thyroid-Eye Clinics in the Management of Graves' Ophthalmopathy. In: Bahn RS, editor. Graves' Disease. New York: Springer; 2015. p. 187-94.

13. Polizzi A, Balsamo A, Bal MO, Taruscio D. Rare diseases research and practice. Endocr Dev. 2014:27:234-56.

14. Perros P, Dayan C, Dickinson AJ, Ezra DG, Hickey JL, Hintschisch C, et al. Future research in Graves' orbitopathy: from priority setting to trial design through patient and public involvement. Thyroid. 2015;25:1181-4.

15. Perros $P$, Kendall-Taylor $P$. Natural history of thyroid eye disease. Thyroid. 1998:8:423-5.

16. Perros P, Žarković M, Azzolini C, Ayvaz G, Baldeschi L, Bartalena L, et al. PREGO (presentation of Graves' orbitopathy) study: changes in referral patterns to European Group On Graves' Orbitopathy (EUGOGO) centres over the period from 2000 to 2012. Br J Ophthalmol. 2015;99:1531-5.

17. Weetman AP, Wiersinga WM. Current management of thyroid-associated ophthalmopathy in Europe. Results of an international survey. Clin Endocrinol (Oxf). 1998;49:21-8.

18. Abraham-Nordling M, Byström K, Törring O, Lantz M, Berg G, Calissendorff J, et al. Incidence of hyperthyroidism in Sweden. Eur J Endocrinol. 2011;165:899-905.
19. Zaletel K, Gaberscek S, Pirnat E. Ten-year follow-up of thyroid epidemiology in Slovenia after increase in salt iodization. Croat Med J. 2011:52:615-21.

20. Laurberg P, Berman DC, Bülow Pedersen I, Andersen S, Carlé A. Incidence and clinical presentation of moderate to severe graves' orbitopathy in a Danish population before and after iodine fortification of salt. J Clin Endocrinol Metab. 2012;97:2325-32.

21. Keiding N. Age-Specific Incidence and Prevalence: A Statistical Perspective. J R Stat Soc Ser A Stat Soc. 1991;154:371-412.

22. Murray CJ, Lopez AD. Quantifying disability: data, methods and results. Bull World Health Organ. 1994;72:481-94.

23. Kruijshaar ME, Barendregt JJ, Hoeymans N. The use of models in the estimation of disease epidemiology. Bull World Health Organ. 2002;80:622-8.

24. http://www.who.int/healthinfo/global_burden_disease/tools_software/en/. Accessed 7 Jan 2017.

25. Brandt F, Almind D, Christensen K, Green A, Brix TH, Hegedüs L. Excess mortality in hyperthyroidism: The influence of preexisting comorbidity and genetic confounding: A Danish nationwide register-based cohort study of twins and singletons. J Clin Endocrinol Metab. 2012;97:4123-9.

26. Vanderpump MP, Tunbridge WM, French JM, Appleton D, Bates D, Clark F, et al. The incidence of thyroid disorders in the community: a twenty-year follow-up of the Whickham Survey. Clin Endocrinol (Oxf). 1995:43:55-68.

27. Berglund J, Ericsson UB, Hallengren B. Increased incidence of thyrotoxicosis in Malmö during the years 1988-90 as compared to the years 1970-74. J Intern Med. 1996;239:57-62.

28. Flynn RW, MacDonald TM, Morris AD, Jung RT, Leese GP. The thyroid epidemiology, audit and research study: thyroid dysfunction in the general population. J Clin Endocrinol Metab. 2004;89:3879-84.

29. Termote K, Decallonne B, Mombaerts I. The influence of prior hyperthyroidism on euthyroid Graves' Ophthalmopathy. J Ophthalmol. 2014;22:426898

30. Eckstein AK, Glowacka D, Mann K, Esser J, Morgenthaler NG. Euthyroid and primarily hypothyroid patients develop milder and significantly more asymmetrical Graves ophthalmopathy. Br J Ophthalmol. 2009;93:1052-6

31. Khoo DH, Eng PH, Ho SC, Morgenthaler NG, Seah LL, Chee SP, et al. Graves' ophthalmopathy in the absence of elevated free thyroxine and triiodothyronine levels: prevalence, natural history, and thyrotropin receptor antibody levels. Thyroid. 2000;10:1093-100.

32. Li Y, Kim J, Diana T, Klasen R, Olivo PD, Kahaly GJ. A novel bioassay for anti-thyrotrophin receptor autoantibodies detects both thyroid-blocking and stimulating activity. Clin Exp Immunol. 2013;173:390-7.

33. Ponto KA, Binder $\mathrm{H}$, Diana $\mathrm{T}$, Matheis $\mathrm{N}$, Otto AF, Pitz $\mathrm{S}$, et al. Prevalence, phenotype, and psychosocial well-being in euthyroid/hypothyroid thyroid-associated orbitopathy. Thyroid. 2015;25:942-8.

34. Soroudi AE, Goldberg RA, McCann JD. Prevalence of asymmetric exophthalmos in Graves' orbitopathy. Ophthalmic Plast Reconstr Surg. 2004;20:224-5.

35. Wiersinga WM, Bleumink M, Saeed P, Baldeschi L, Prummel MF. Is sleeping position related to asymmetry in bilateral Graves' ophthalmopathy? Thyroid. 2008;18:541-4

36. Bartley GB. The epidemiologic characteristics and clinical course of ophthalmopathy associated with autoimmune thyroid disease in Olmsted County, Minnesota. Trans Am Ophthalmol Soc. 1994;92:477-588.

37. Prummel MF, Bakker A, Wiersinga WM, Baldeschi L, Mourits MP, KendallTaylor $P$, et al. Multi-center study on the characteristics and treatment strategies of patients with Graves' orbitopathy: the first European Group on Graves' Orbitopathy experience. Eur J Endocrinol. 2003;148:491-5.

38. Daumerie C, Duprez T, Boschi A. Long-term multidisciplinary follow-up of unilateral thyroid-associated orbitopathy. Eur J Intern Med. 2008;19:531-6.

39. Bartalena L, Chiovato L. Graves'-like orbitopathy: do not forget IgG4-related disease. J Endocrinol Invest. 2014:37:1233-5.

40. Tiegs-Heiden CA, Eckel $\sqcup$, Hunt CH, Diehn FE, Schwartz KM, Kallmes DF, et al. Immunoglobulin G4-related disease of the orbit: imaging features in 27 patients. AJNR Am J Neuroradiol. 2014;35:1393-7.

41. Bartley GB, Fatourechi V, Kadrmas EF, Jacobsen SJ, Ilstrup DM, Garrity JA et al. Long-term follow-up of Graves ophthalmopathy in an incidence cohort Ophthalmology. 1996:103:958-62.

42. Terwee C, Wakelkamp I, Tan S, Dekker F, Prummel MF, Wiersinga W. Long-term effects of Graves' ophthalmopathy on health-related quality of life. Eur J Endocrinol. 2002;146:751-7. 
43. http://ec.europa.eu/health/files/eudralex/vol-1/reg_2000_141/reg_2000_ 141 en.pdf. Accessed 7 Jan 2017.

44. Aymé S, Bellet B, Rath A. Rare diseases in ICD11: making rare diseases visible in health information systems through appropriate coding. Orphanet J Rare Dis. 2015;10:35.

45. http://www.ema.europa.eu/docs/en_GB/document_library/Other/2015/08/ WC500191754.pdf. Accessed 7 Jan 2017.

Submit your next manuscript to BioMed Central and we will help you at every step:

- We accept pre-submission inquiries

- Our selector tool helps you to find the most relevant journal

- We provide round the clock customer support

- Convenient online submission

- Thorough peer review

- Inclusion in PubMed and all major indexing services

- Maximum visibility for your research

Submit your manuscript at www.biomedcentral.com/submit
Biomed Central 